\title{
Spatial Comprehension Exercise System with 3D CG of Toy Model for Disabled Children
}

\author{
Kohei Arai ${ }^{1}$ \\ 1 Graduate School of Science and \\ Engineering \\ Saga University \\ Saga City, Japan
}

\author{
Taiki Ishigaki ${ }^{1}$ \\ 1 Graduate School of Science and \\ Engineering \\ Saga University \\ Saga City, Japan
}

\author{
Mariko Oda ${ }^{2}$ \\ 2 Hagoromo International \\ University \\ Sakai City, \\ Osaka, Japan
}

\begin{abstract}
Spatial comprehension exercise system with ThreeDimensional Computer Graphics: 3D CG of toy model for disabled children is proposed. In order to improve spatial comprehension in an attractive manner, a toy model is created together with building block model. Through experiments, it is confirmed that the spatial comprehension is improved for the disabled children remarkably.
\end{abstract}

Keywords-Spatial Comprehension; Toy model; Augmented reality; Computer graphics

\section{INTRODUCTION}

E-Learning Framework for Learning Disabled Children is well defined [1]. Although there are so many types of the Learning Disability: LD [2]-[4], very few paper deals with learning content spatial comprehension. It's really hard to pick up objects and take a look at the back view of the objects for disabled children. Therefore, there is a strong demand of learning contents which allow improvement of spatial comprehension.

Digital content creation, learning content retrieval, collaborating learning system, learning system utilizing computer input by human eyes only for disabled persons are proposed previously [5]-[20]. Such those contents and systems would be better to be used for disabled children. One of the difficulties for disabled children to learn is spatial comprehension. Spatial comprehension needs practices with physically acting to an object. Although, it is easy to conduct such practices for able children, it is not so easy for disabled children. This paper deals with learning system based on 3D CG for spatial comprehension practices in particular for disabled children.

As for the related research works, National Institute of Special Needs Education: NISNE created Web Based Learning Contents of Japanese characters, numerical counting, recreations for disabled children ${ }^{1}$. Also, Yamaguchi Education Support Center (Prefectural local government) created digital contents for disabled children ${ }^{2}$. Furthermore,
Japan Science and Technology Agency: JST provides digital contents of Science and technology for disabled children ${ }^{3}$. Kanagawa prefectural education support center provides digital contents and materials for disabled children ${ }^{4}$. PROP Station provides education software tools, learning contents for a variety of disability ${ }^{5}$. Most of useful digital contents for disabled children can be accessible to the site ${ }^{6}$. Although there are many 3D CG contents, there is small number of 3D CG content for spatial comprehension exercises for disabled children. It is hard to learn spatial comprehension for disabled children.

In order to improve spatial comprehension in an attractive manner, a toy model is created together with building block model. Through experiments with several disabled children, it is confirmed that the spatial comprehension is improved for the disabled children remarkably.

The following section describes the proposed method and system followed by the procedure of experiments. Then the experimental results are described together with some remarks. Finally, conclusion is described together with some discussions and future research works.

\section{PROPOSED METHOD AND SYSTEM}

\section{A. Toy Model}

Fig.1 shows one of the examples of the proposed toy model. Practice system of spatial comprehension should be attractive. Therefore, toy model is created. Spatial comprehension capability is improved through playing with the toy model. Through this escape game, disabled children are getting familiar with spatial comprehension pleasantly. There are three elements for the escape game, character, sword and capsule as shown in Fig.2. The key components of the proposed toy model are (a) Realistic motion of the objects, (b) Learning in an attractive manner. Therefore, physical model of the objects have to be created precisely. Also, it has to be represented that jumping motion of the character when the sword is inserted into the correct hole. Then the proposed learning content becomes attractive.

\footnotetext{
${ }^{3}$ http://rikashien.jst.go.jp/support/index.html

${ }^{4}$ http://www.edu-

ctr.pref.kanagawa.jp/kanabox/modules/mydownloads/viewcat.php?cid=1

${ }_{6}^{5} \mathrm{http} / / /$ www.prop.or.jp/challenged/open/heart/heart-jp133-1.html

${ }^{6}$ http://www.tenji.ne.jp/kyozai/list.php
}

\footnotetext{
${ }^{1}$ http://www.nise.go.jp/wakaru/index.html

${ }^{2}$ http://shien.ysn21.jp/teacher/kyoiku_link.html\#spedu
} 


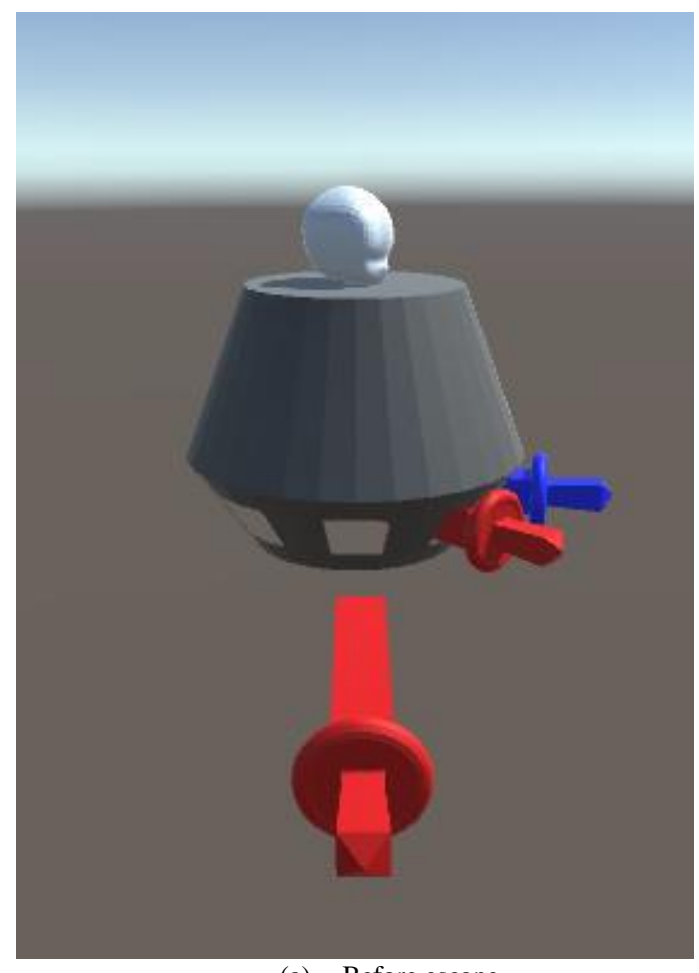

(a) Before escape

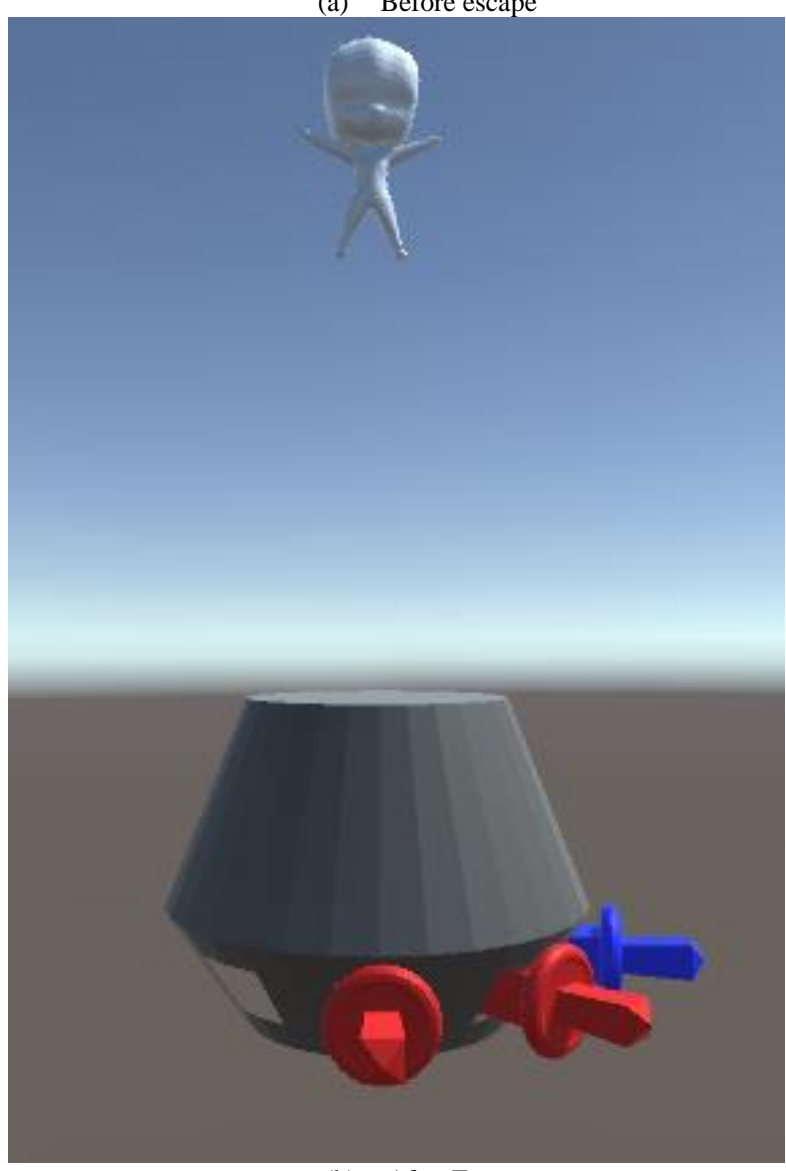

(b) After Escape

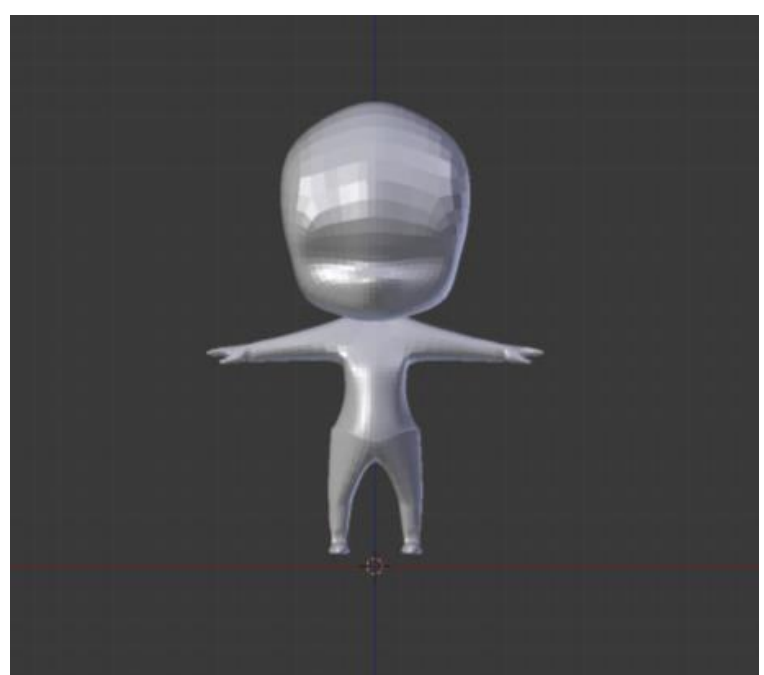

(a) Character

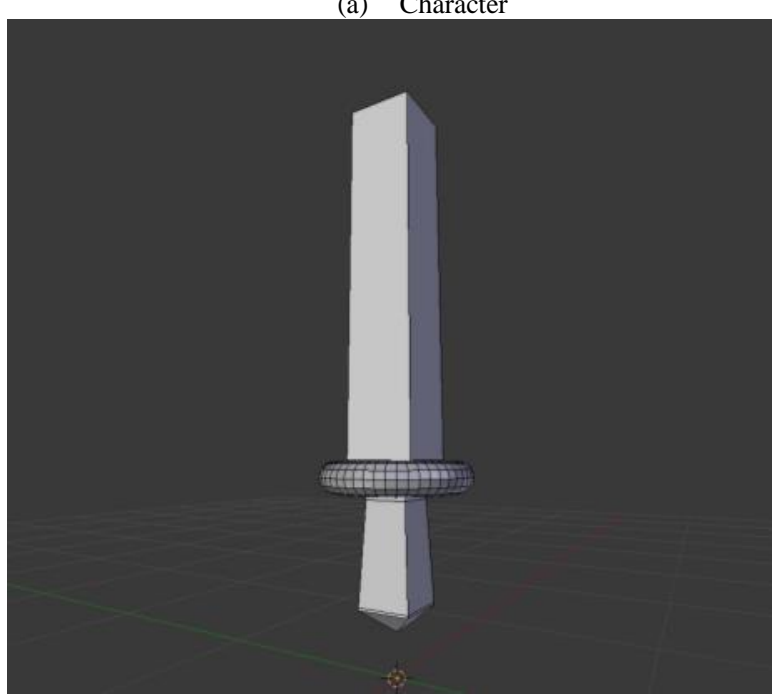

(b) Sword

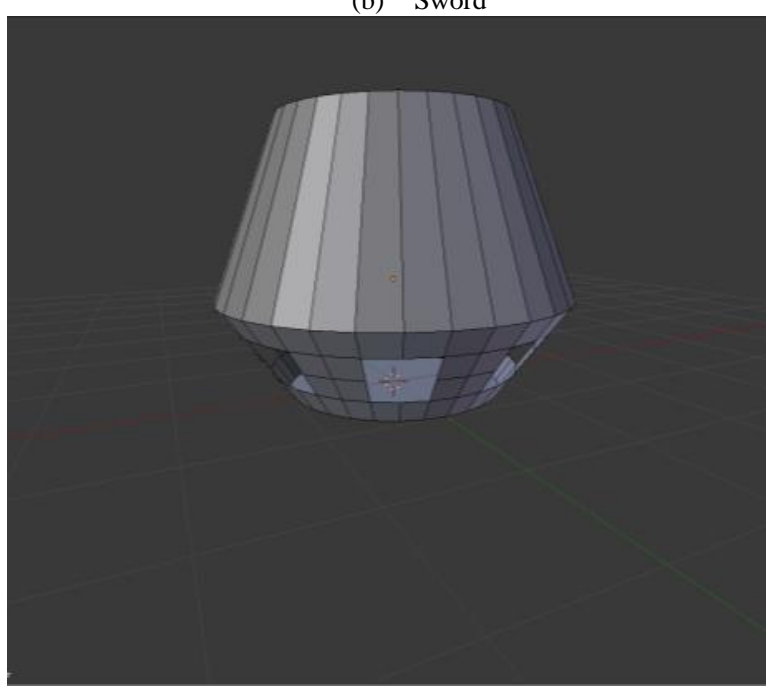

(c) Capsule

Fig. 2. Elements of the escape game

Fig. 1. Toy model 
Rotation of the sword, stab the sword can be selected by clicking the right and the left button as shown in Fig.3. At the beginning, the character is in the capsule. Then the sword appears followed by manipulation of the sword.

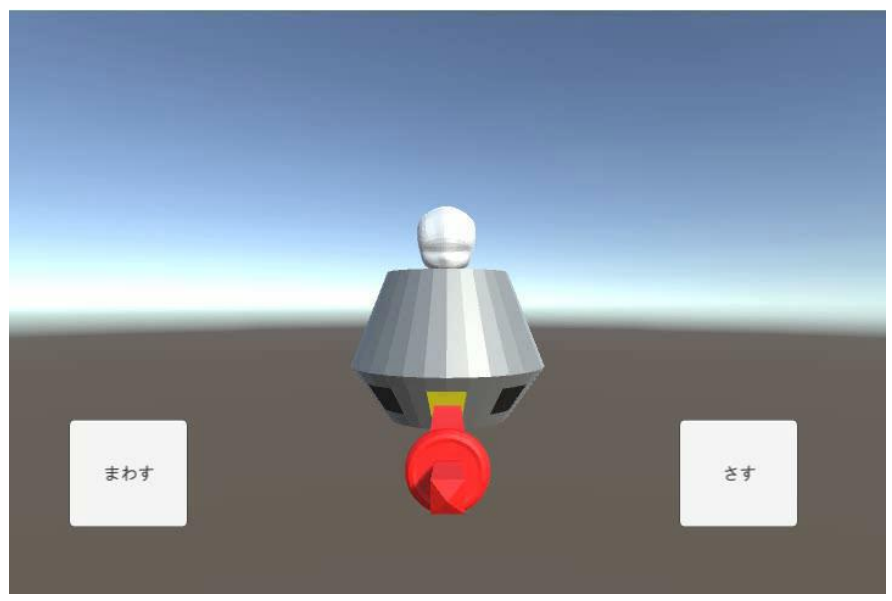

Fig. 3. Escape game

At the bottom of the capsule, there are the holes of which the shape of the hole is matching to the cross section of the sword. Learners manipulate the capsule by rotating for matching the sword to one of the holes, then put the sword in to the hole. If the sword put in bingo hole, then the character jumped out from the capsule. It is not so easy to put the sword in the hole. It is required spatial comprehension for matching the sword to the hole. Through practices with the toy model, spatial comprehension is getting better.

\section{B. Building Block}

Another spatial comprehension practice model proposed here is "Building Block". Pile up blocks needs spatial comprehension. Fundamental interface between disabled children and PC is shown in Fig.4.

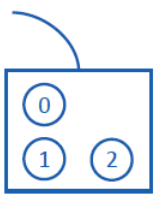

Touch-Pad
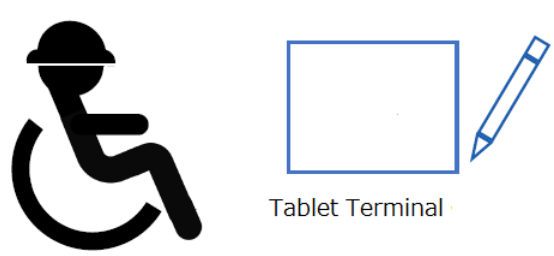

Tablet Terminal

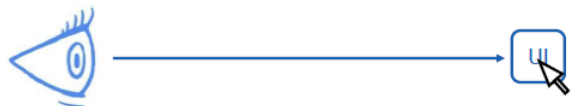

Gaze Input System

Fig. 4. User interface of the proposed spatial comprehension practices

Namely, touch pad and tablet terminals are available for the disabled children who can use their hands and fingers. Also, gaze input can be used for the disabled children who cannot use their hands and fingers.

Fig.5 shows screen shot image of the menu. At the topright, there is the radio-button for getting started. The example of the questions is available through the button user the start button. Hold the current situation can be done with the top-left button. If the learner would like to increase another block, the button under the hold button is used.

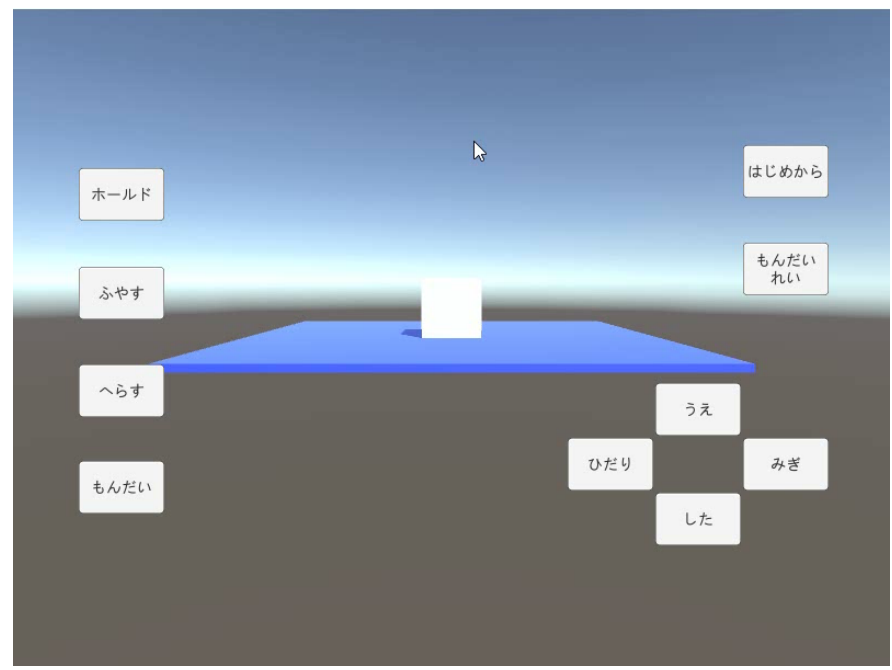

Fig. 5. Screenshot image of the proposed building block practice system

Meanwhile, the number of blocks can be reduced by one by one basis with the button under the increase button. Also, the questions are available with the button under the reduce button. When the increase button is clicked, then one block appears at the top of the screen. It, then is falling to the base plane of which the building blocks are piled up. Physical model is considered. Therefore, felt down block touches down on the base plane or on the previously situated block. Collision occurs between the additional block and the base plane or the previous blocks as shown in Fig.6.

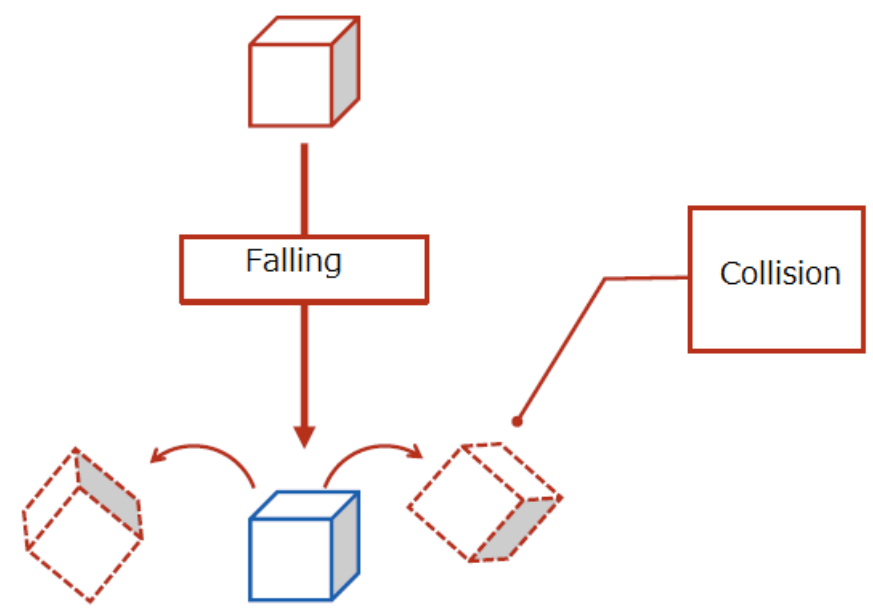

Fig. 6. Additional block is felt down (collision occurs with the other blocks)

The blocks may be translated on the right, the left, the upward and the downward by using the buttons situated at the right bottom of the screen image in Fig.5. Learners may select practice modes by clicking the top left button in the Fig.7. Learners also may restart the building block practice by clicking the top right button in Fig.7.

Questions are available with the bottom left button while the examples of the questions can be referred with the bottom right button in Fig.7. The block in concern can be translated 
by clicking arrow buttons in the direction of right, left, upward and downward.

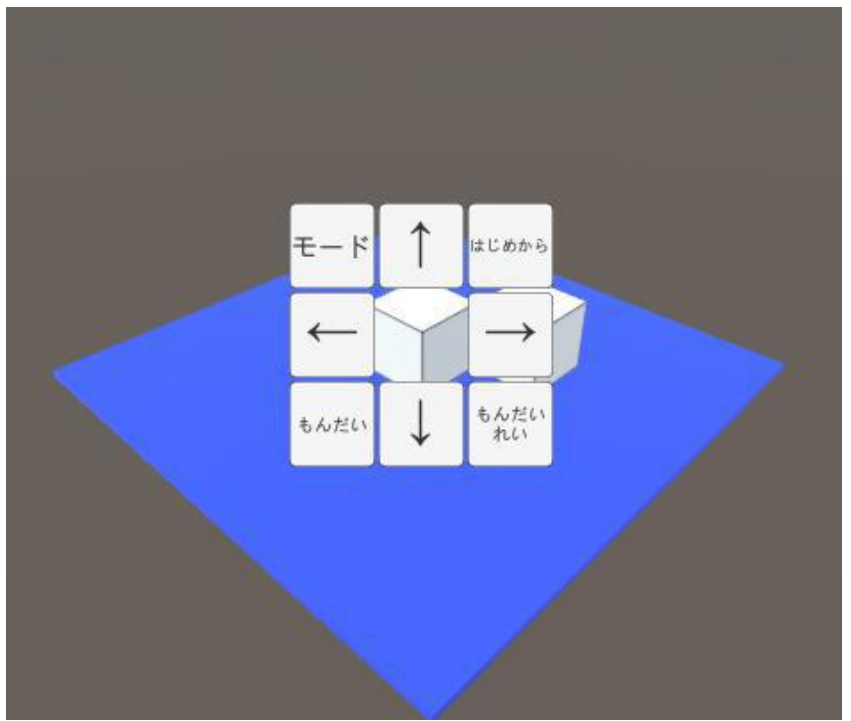

Fig. 7. Screen shot image of the sub menu

It is also available to show the building blocks in the $3 \mathrm{D}$ space as shown in Fig.8. The different aspects of view images are available by changing the viewing angles as shown in Fig.8.
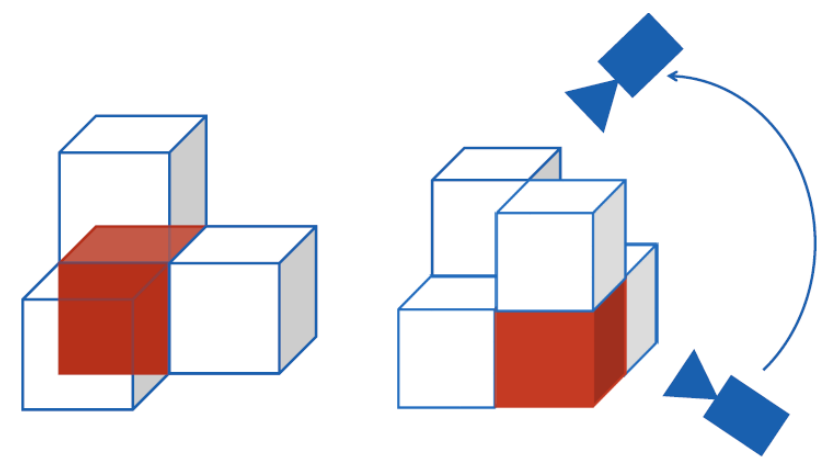

(a) 3D display

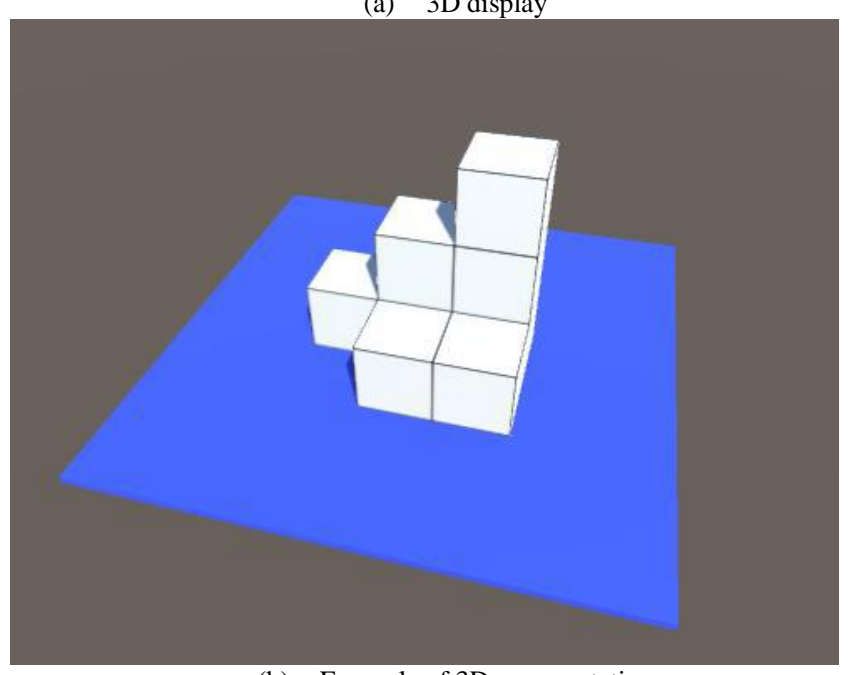

(b) Example of 3D representation

Fig. 8. Representation of building blocks in the 3D space
Through building block practices, learners can improve their spatial comprehension such as those situations of blocks which are shown in Fig.9

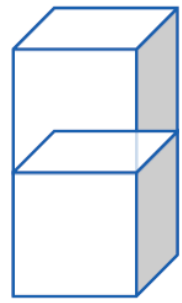

(a)

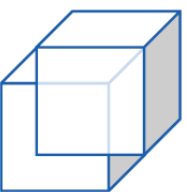

(b)
Fig. 9. Improve their spatial comprehension such as those situations of blocks

The block situations which are shown in Fig.9 are not so comprehensive. By representing the building blocks in the 3D space, the block situations can be comprehensive.

Three examples of the questions are shown in Fig.10. The example of Fig.10 (a) askes which block representation in 3D space is the most appropriate real situation of the block shown at the top. Learner is asked to build the blocks as is matched to the 3D image of building blocks shown in the top of Fig.10 (b). On the other hand, learner is asked the number of blocks in the 3D building blocks as shown in Fig.10 (c).

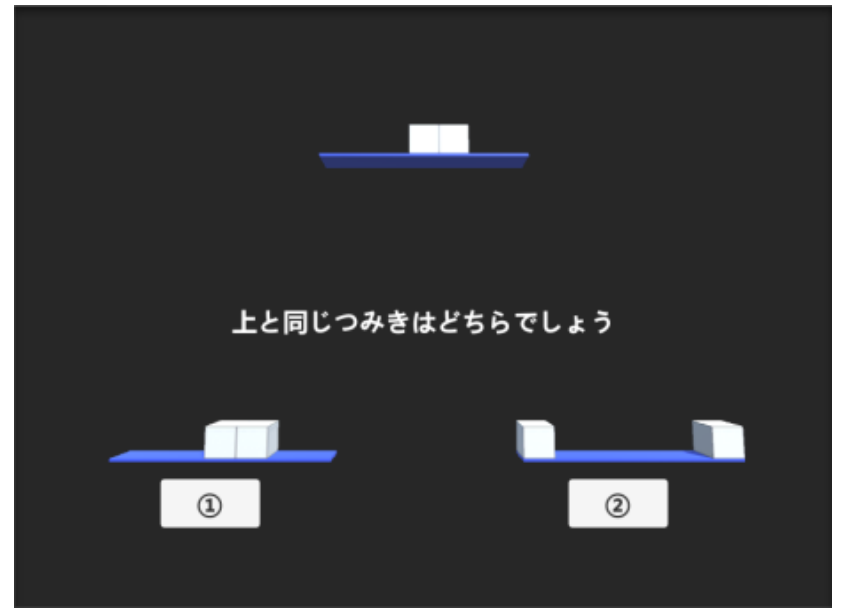

(a) Which is the appropriate block situation

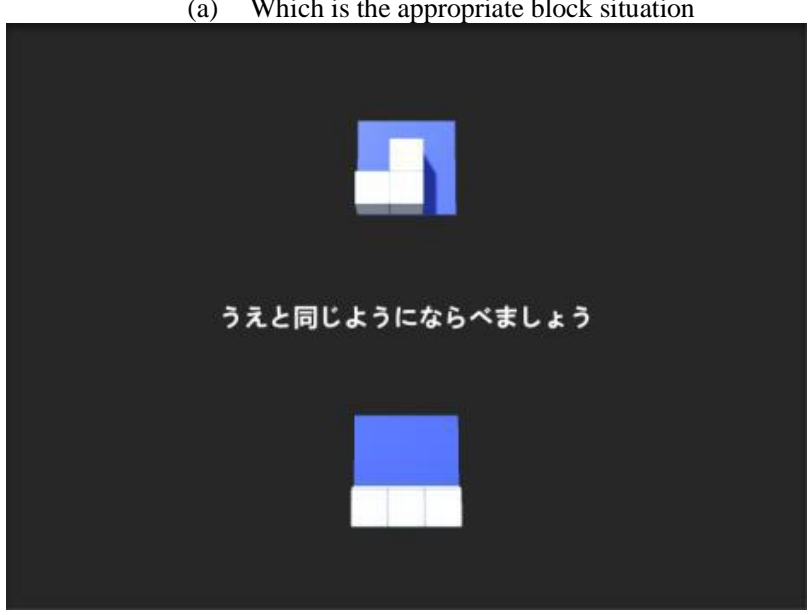

(b) Put the blocks 


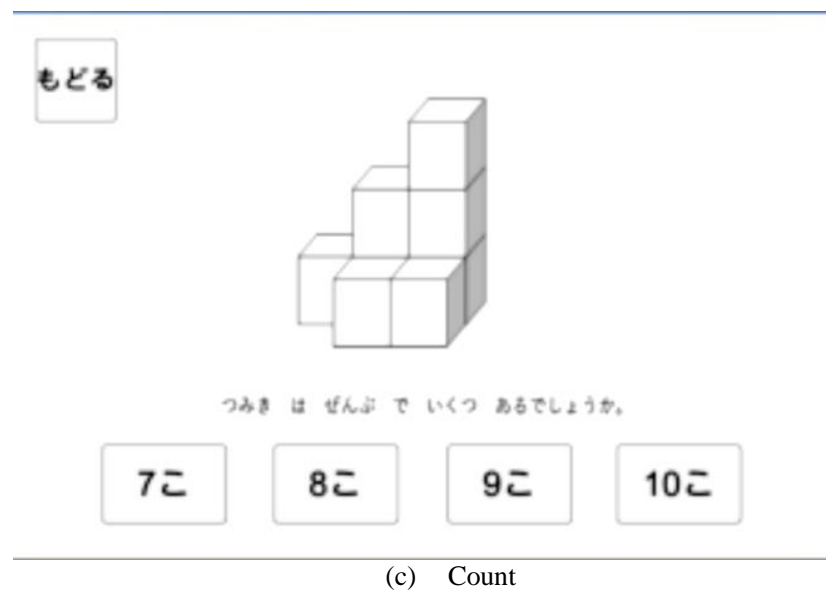

Fig. 10. Examples of the questions

The key issues of the proposed learning content creation are (a) Realistic motion of the blocks in accordance with physical model, (b) encouragement for the disabled children with attractive question and answer.

\section{EXPERIMENTS}

Photos of the spatial comprehension practices are shown in Fig.11. In the practice, the disabled children can pick up and drop the blocks in the 3D CG world. The block motion is natural in the CG world so that the proposed learning content is attractive. Question and answer is also attractive. They can imagine the blocks which are situated behind the blocks through practices. Disabled children also can see the blocks from the different aspects. This is very helpful to improve their spatial comprehension.

As the experimental results, all the disabled children made correct answer to the questions which are illustrated in Fig.10 (a), (b) and (c) perfectly after the practices. Therefore, it may said that it is confirmed that the spatial comprehension is improved for the disabled children remarkably.

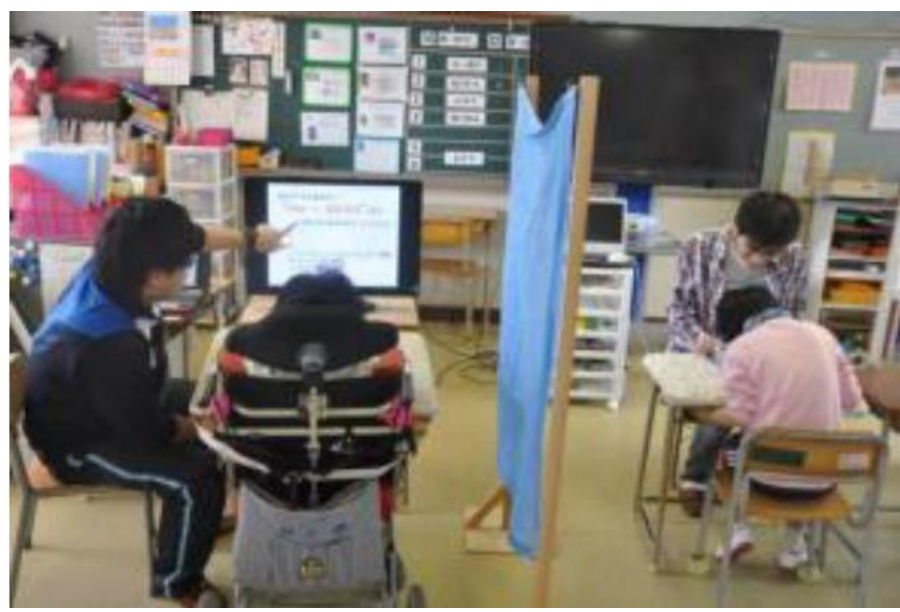

(a)

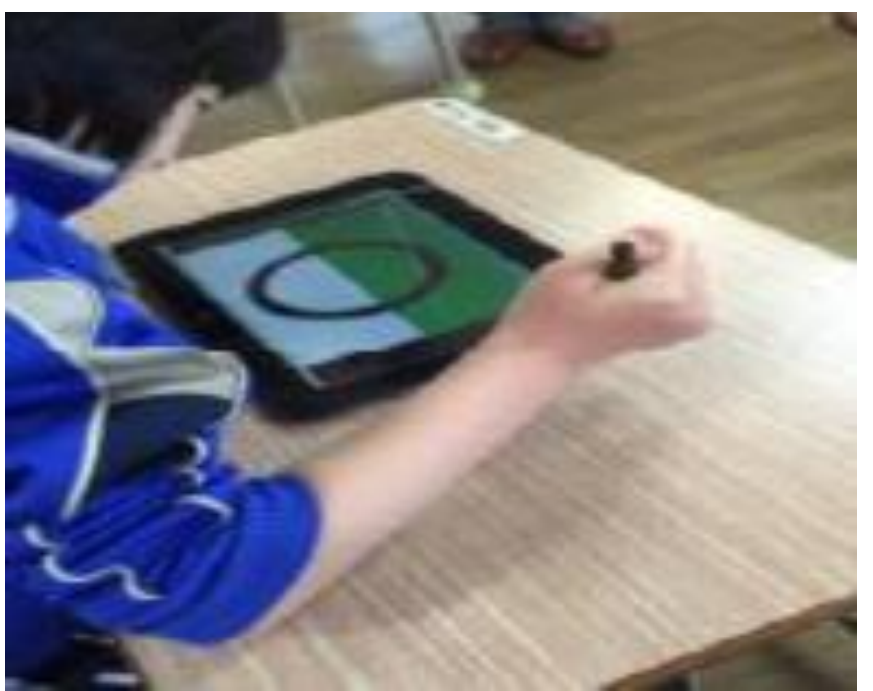

(b)

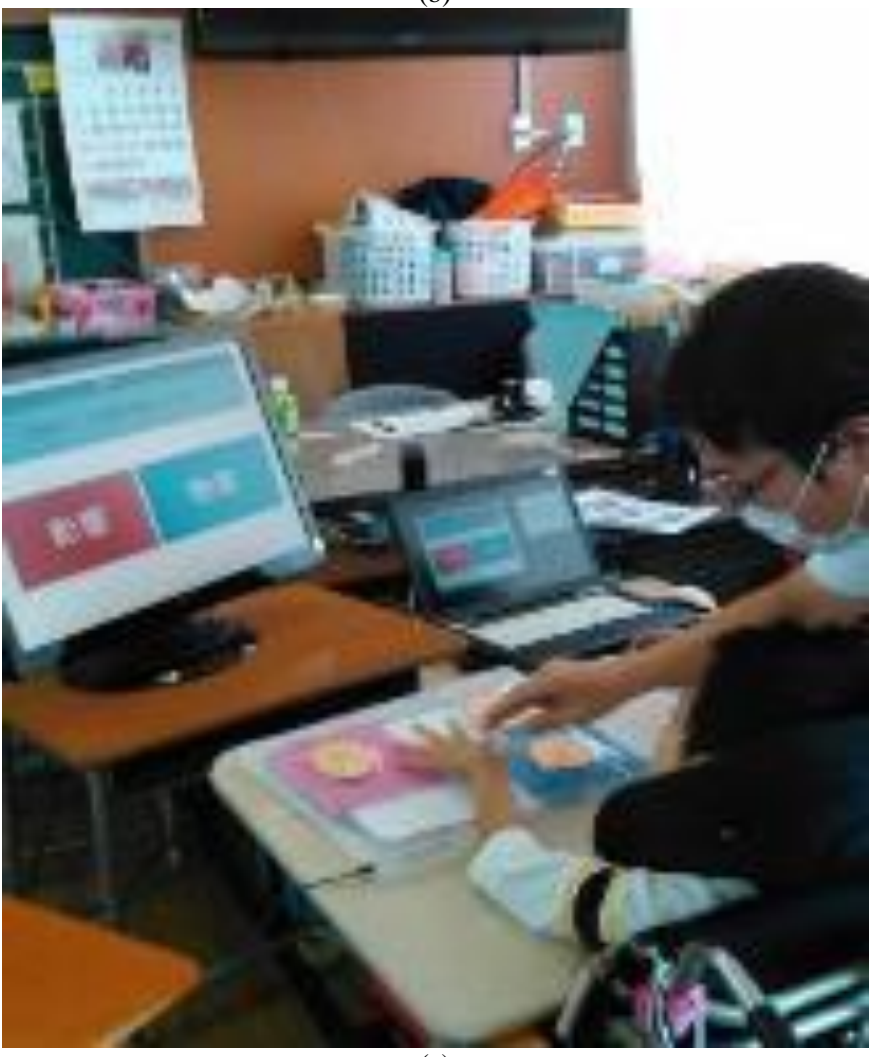

(c)

Fig. 11. Photos of the spatial comprehension practices

\section{CONCLUSION}

Spatial comprehension exercise system with ThreeDimensional Computer Graphics: 3D CG of toy model for disabled children is proposed. In order to improve spatial comprehension in an attractive manner, a toy model is created 
together with building block model. Experiments with building block model are conducted.

As the experimental results, all the disabled children made correct answer to the questions, (a) askes which block representation in 3D space is the most appropriate real situation of the block shown at the top, (b) learner is asked to build the blocks as is matched to the 3D image of building blocks, (c) learner is asked the number of blocks, perfectly after the practices. Therefore, it may say that it is confirmed that the spatial comprehension is improved for the disabled children remarkably.

Further investigations are required for confirmation of improvement of spatial comprehension through achievement tests.

\section{ACKNOWLEDGMENT}

The author would like to thank research staff of the Kurume Institute of Technology for their support of the research works and the experiments.

\section{REFERENCES}

[1] Z. Pirani, V. Molvizadah, M.A. Sayyed, E-Learning Framework for Learning Disabled Children, International Journal of Computer Applications, 63, 19, 38-42, 2013.

[2] Rhodes, J. \& Milby, T. M. Teacher-Created Electronic Books: Integrating Technology to Support Readers with Disabilitites. The Reading Teacher, 61(3), 255-259, 2007.

[3] Kimberly L. Keith., Assistive Technology for Students with Learning Disabilities, J. Reach learn. Res 3 1276-1282, 2006.

[4] Beverly Park Woolf, A Roadmap for Education Technology funded by the National Science Foundation \# 0637190, The Computing Community Consortium (CCC), managed by the Computing Research Association (CRA) with a sub-award to Global Resources for Online Education, Beverly Park Woolf, P. I, pg 69, 2010.

[5] Kohei Arai and Tolle Herman, Module based content adaptation of composite e-learning content for delivering to mobile learners, International Journal of Computer Theory and Engineering, 3, 3, 382387, 2011.

[6] Kohei Arai, Ronny Mardiyanto, Eye-based human-computer interaction allowing phoning, reading e-book/e-comic/e-learning, Internet browsing and TV information extraction, International Journal of Advanced Computer Science and Applications, 2, 12, 26-32, 2011.

[7] Kohei Arai, Herman Tolle, Efficiency improvements of e-learning document search engine for mobile browser, International Journal of Research and Reviews on Computer Science, 2, 6, 1287-1291, 2011

[8] K.Arai, T.Herman, Efficiency improvement of e-learning document search engine for mobile browser, International Journal of Research and review on Computer Science, 2, 6, 1287-1291, 2012

[9] K.Arai, T.Herman, E-learning document search method with supplemental keywords derived from keywords in meta-tag and descriptions which are included in the header of the first search result, International Journal of Advanced Computer Science and Applications, 3, 4, 99-104, 2012
[10] K.Arai, Method for leaning efficiency improvements based on gaze location notifications on e-learning content screen display, International Journal of Advanced Research in Artificial Intelligence, 1, 3, 1-6, 2012.

[11] K.Arai, T.Herman, Video searching optimization with supplemental semantic keyword for e-learning video searching, International Journal of Research and Review on Computer Science, 3, 3, 1640-1644, 2012

[12] K.Arai, E-learning system which allows students' confidence level evaluation with their voice when they answer to the questions during achievement tests, International Journal of Advanced Computer Science and Applications, 3, 9, 80-84, 2012.

[13] Kohei Arai, Anik Nur Handayani, E-learning system utilizing learners' characteristics recognized through learning process with Open Simulator, International Journal of Advanced Research in Artificial Intelligence, 2, 4, 8-12, 2013.

[14] Kohei Arai, Anik Nur Handayani, Question answering for collaborative learning with answer quality predictor, International Journal of Modern Education and Computer Science, 5, 5, 12-17, 2013.

[15] Kohei Arai, Lecture's e-Table (server terminal) which allows monitoring the location at which each student is looking during lessons with elearning contents through client terminals, International Journal of Advanced Research in Artificial Intelligence, 2, 6, 40-45, 2013.

[16] Kotaro Taguchi, Mariko Oda, Hiroshi Kouno Seio Oda, Kohei Arai, Development of learning support software with CG animations for intellectually disabled children, Journal of Education System and Information Society of Japan, 30,1, 48-56, 2014

[17] Kohei Arai, Anik Nur Handayani, Question Answering for collaborative learning with answer quality prediction, International Journal of Modern Education and Computer Science, 5, 5, 12-17, 2013

[18] Kohei Arai, Free Open Source Software: FOSS based e-learning system together with blended learning system, International Journal of Advanced Research in Artificial Intelligence, 2, 11, 9-16, 2013.

[19] K.Arai, Anik Nur Handayani, Predicting quality of answer in collaborative question answer learning, International Journal of Advanced Research in Artificial Intelligence, 3, 2, 23-26, 2014.

[20] Kohei Arai, Yahoo! Search and web API utilized mashup based elearning content search engine for mobile learning, International Journal of Advanced Research on Artificial Intelligence, 4, 6, 1-7, 2015

\section{AUTHORS PROFILE}

Kohei Arai, He received BS, MS and PhD degrees in 1972, 1974 and 1982, respectively. He was with The Institute for Industrial Science and Technology of the University of Tokyo from April 1974 to December 1978 also was with National Space Development Agency of Japan from January, 1979 to March, 1990. During from 1985 to 1987, he was with Canada Centre for Remote Sensing as a Post Doctoral Fellow of National Science and Engineering Research Council of Canada. He moved to Saga University as a Professor in Department of Information Science on April 1990. He was a councilor for the Aeronautics and Space related to the Technology Committee of the Ministry of Science and Technology during from 1998 to 2000. He was a councilor of Saga University for 2002 and 2003. He also was an executive councilor for the Remote Sensing Society of Japan for 2003 to 2005. He is an Adjunct Professor of University of Arizona, USA since 1998. He also is Vice Chairman of the Commission "A" of ICSU/COSPAR for 8 years, 2008-2016 then he is now award committee member of ICSU/COSPAR. He wrote 37 books and published 570 journal papers. He received 30 of awards including ICSU/COSPAR Vikram Sarabhai Medal in 2016, and Science award of Ministry of Mister of Education of Japan in 2015. He is now Editor-in-Chief of IJACSA and IJISA. http://teagis.ip.is.saga-u.ac.jp/index.html 